\title{
Spatial and temporal variations of winter discharge under climate change: Case study of rivers in European Russia
}

\author{
E.A. TELEGINA \\ Department of Land Hydrology, Lomonosov Moscow State University, GSP-1, Leninskie Gory, Moscow, 119991, \\ Russian Federation \\ teleginakaterina@,gmail.ru
}

\begin{abstract}
An important problem in hydrology is the re-evaluation of the current resources of surface and underground waters in the context of ongoing climate changes. The main feature of the present-day changes in water regime in the major portion of European Russia (ER) is the substantial increase in low-water runoff, especially in winter. In this context, some features of the spatial-temporal variations of runoff values during the winter low-water period are considered. Calculations showed that the winter runoff increased at more than $95 \%$ of hydrological gauges. Changes in the minimum and average values of runoff during winter lowwater period and other characteristics are evaluated against the background of climate changes in the recent decades. The spatial and temporal variability of winter runoff in European Russia is evaluated for the first time.
\end{abstract}

Key words climate changes, water balance, winter low-water runoff, freezing depth, thaws

\section{INTRODUCTION}

Considerable increase in surface air temperature has been recorded in European Russia (ER; Fig. 1) since the late 1970s. The average rate of annual temperature increase for the considered territory is $0.53^{\circ} \mathrm{C} / 10$ years, which is mostly due to the mean cold season temperatures $\left(0.45-0.6^{\circ} \mathrm{C} / 10\right.$ years $)$. In the recent 50 years, a higher moistening level has been recorded in ER areas north of $50^{\circ} \mathrm{N}$, where the share of liquid precipitation in the cold season has also increased. This is largely due to the more intense circulation processes in the North Atlantic, which affect the transfer of cyclones into the central regions of Russia (Kislov and Babin 2008).

The features of modern climate have led to an increase in the duration and the number of thaws and a general decrease in the annual cold-period duration in ER. These tendencies lead to a decrease in soil freezing depth, as registered on agrometeorological stations in all regions of ER. The most rapid rise in this characteristic was observed from the 1980s to 2000, which coincides with the period of maximum values of the winter runoff. The general decrease in soil freezing depth is reflected in an increase in the minimum annual temperature of soil layers deeper than 60 cm (RosHydromet 2012, 2013; Fig. 2).

The increase in the number of thaws in winter leads to groundwater level rise and a decrease in snow cover water equivalent in the catchment area. The result is a decrease in spring flood runoff. According to the State Hydrological Institute (Georgievskii 2005), groundwater level rose by $50-130 \mathrm{~cm}$ at the majority of gauges in ER during the recent decades compared to the previous period. Therefore, we observe a redistribution of water masses between the main phases of the hydrological regime.

\section{STUDY AREA}

The study objects are the basins of the major rivers of European Russia (ER): the rivers of Pechora, Mezen, Onega, Northern Dvina, Volga and Don (Fig. 3). The large territory, the difference in atmospheric circulation forms, as well as mountains and hills determine the diversity of local landscapes and climates. This leads to differences in the formation of runoff and other elements of the water balance in the natural and climatic zones of this territory. Therefore, the main purpose of this work is to study and analyse the spatial and temporal variability of winter runoff parameters, to identify the major factors that, under climate change, could lead to an increase in the flow in winter, and to assess the extent of this influence. European Russia includes 


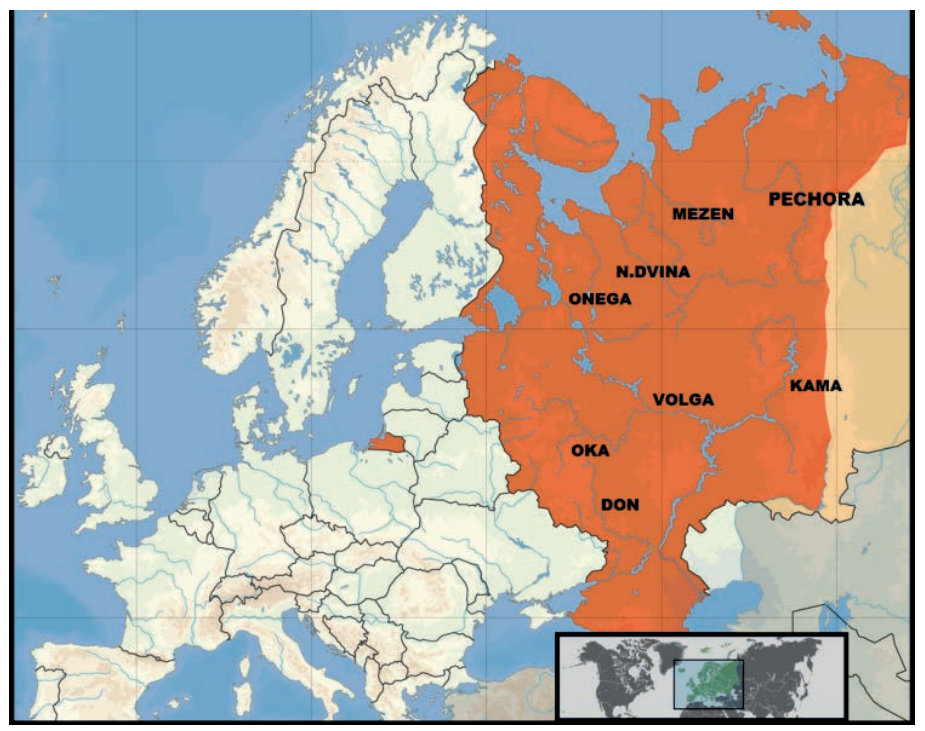

Fig. 1 European Russia

(a)
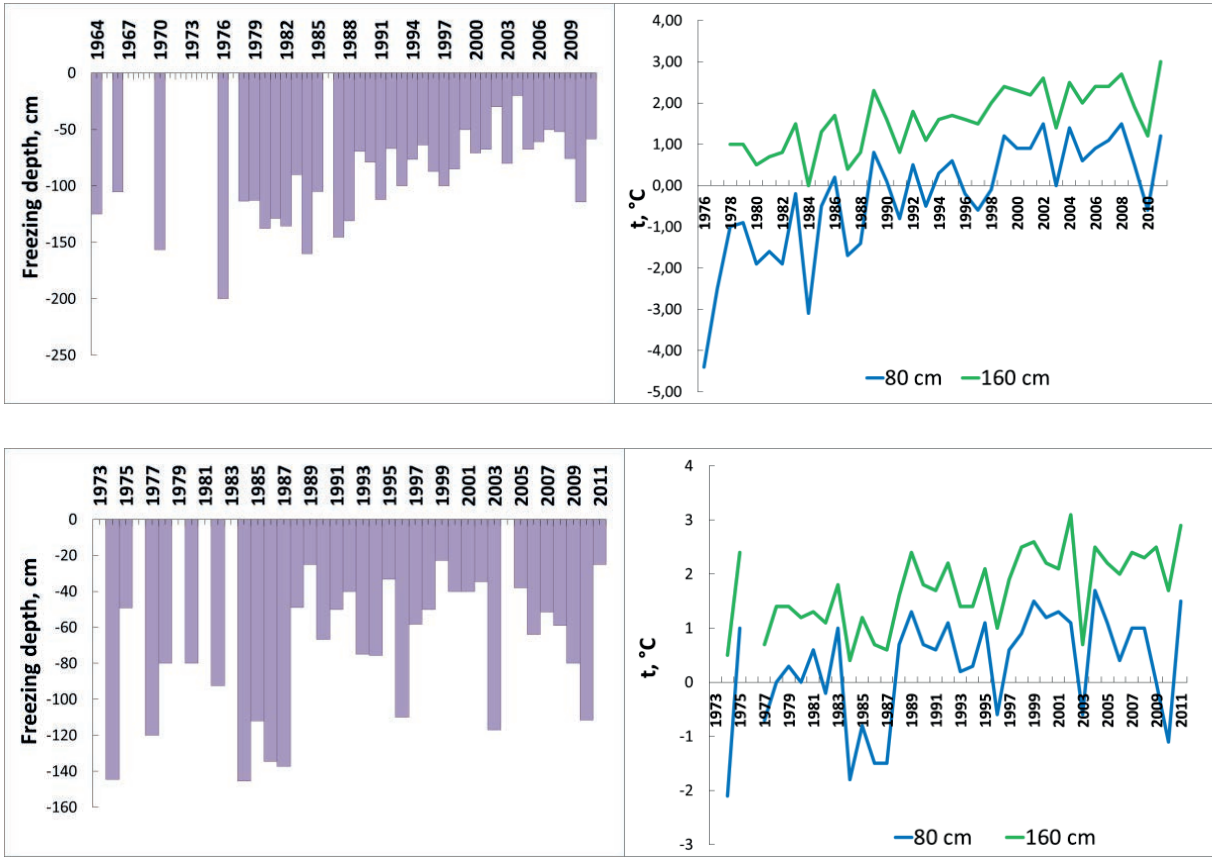

Fig. 2 (a) Left: Freezing depth at the hydrological stations in the middle reaches of the Volga R. (Sergach, Piana R.); right: minimum soil temperature during winter at depths of 80 and $160 \mathrm{~cm}$. (b) Left: freezing depth at the hydrological stations in the basin of the Don R. (Elec, Sosna R.); right: changes in the minimum soil temperature during winter at depths of 80 and $160 \mathrm{~cm}$.

the western areas of Russia, which border with Finland, the Baltic countries, Belarus and Ukraine. ER is about $3960000 \mathrm{~km}^{2}$ in area, spanning across 38\% of Europe. Its eastern border is the Ural Mountains, while in the south, it borders with Kazakhstan.

\section{DATA AND METHODS}

Calculations showed an increase in winter runoff at more than $95 \%$ of hydrological gauges; at some rivers it reaches $100 \%$. The choice of these watersheds allows tracing of the features of formation of winter runoff on rivers of different size under different physiographic conditions within ER. Changes in the characteristics of winter runoff were analysed for the period from 1975 to 2010 and compared with the period from 1945 to 1974 . The established ascending trend was 


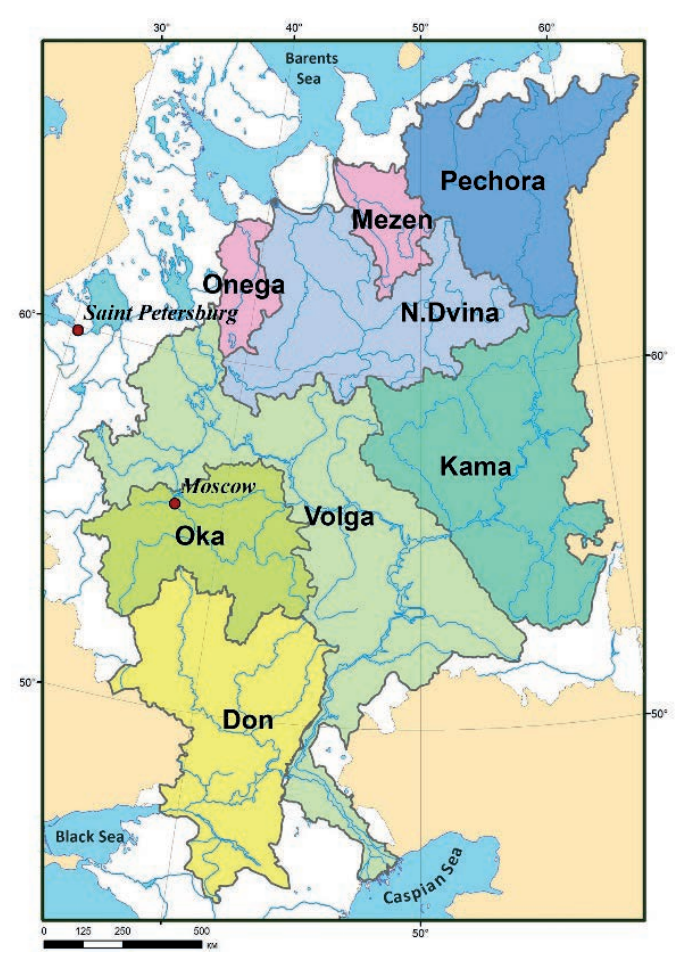

Fig. 3 Studied river basins of European Russia.

significant for $82 \%$ of hydrological gauges in the rivers of the Volga and Don basins and for $43 \%$ of the rivers in the northern ER.

The characteristics analysed in this study include the average, minimum, and maximum water discharge for winter low-water flow, the intensity and duration of winter runoff depletion, the variability of water regime in the studied rivers, the date of minimum water discharge in winter, the duration of winter low-water period, and others.

Changes in the hydrological and meteorological characteristics were estimated for the period 1945-2010. Analysis of changes in the characteristics of winter low-water flow was made for 1975-2010 compared with 1945-1975, and separately for the two time periods.

The winter season for Russia was assumed to last from November to March. However, spring flood in some rivers in the southern ER may start in February. On the other hand, the period of low winter runoff for rivers of the northern ER may last until April or May. In addition, the rivers in the Don and Volga basins sometimes have high water flow in November and December. This is due to delayed or continuing recession of floods and is not associated with winter thaws. Thus, there is a problem with the isolation of winter low-water period and the analysis of data on a vast and diverse area. As a result, the boundaries of winter low-water runoff periods were determined by using the average monthly water discharge for each year of the research period. The period of formation of winter low water consists of two parts: a depletion during discharge (decay curve), and the period of gradually increasing flow after passing through a minimum.

In this study, the long-term variability of a winter low-water runoff was assessed. The analysed hydrological gauges number 140. For each year in the study period 1945-2010, boundaries of the winter low-water period were determined, the duration of this period was calculated, and the average for the winter low-water discharge and the modulus of flow were evaluated. The change in the winter runoff low was calculated as the ratio of the average monthly water discharges for 1975-2010 to that for 1945-1974. The change was expressed as percent. The obtained data were used to estimate the spatial and temporal variations of the volumes of the winter flow and its major characteristics.

The investigated river basins occupy the major part of ER. They are located in different natural and climatic zones. To simplify the comparison, they were divided into three groups: 
(1) rivers of the northern part (Onega, Mezen, Pechora, and Northern Dvina); (2) the Volga basin (Upper Volga, Lower Volga, Kama, and Oka); (3) the Don basin.

\section{RESULTS AND DISCUSSION}

Calculations showed that more than $95 \%$ of hydrological gauges have increasing winter runoff. In other words, there is a positive trend in its changes. For $82 \%$ of hydrological gauges on rivers in the Volga and Don basins, and for $43 \%$ of hydrological gauges on rivers in the northern ER, this ascending trend was significant. Table 1 shows changes in the volumes of the winter runoff averaged for chosen areas.

Table 1 Changes in the volumes of winter runoff for period from 1975 to 2010 relative to the period from 1945 to 1974 , in percent.

\begin{tabular}{ll}
\hline Areas & Changes in the volume of winter runoff, \% \\
\hline Upper Volga & 48 \\
Kama R. Basin & 38 \\
Lower Volga & 72 \\
Oka R. Basin & 57 \\
Don R. Basin & 71 \\
River basins in the northern ER & 8 \\
\hline
\end{tabular}

Watersheds of the rivers, which flow in southern ER, are exposed to climate change more than rivers basins in the northern ER. The magnitude of changes in the water regime of the rivers decreases from the south to the north in the territory under study. Thus, the increase in winter water abundance from 1975 to 2010 varied from $20 \%$ to more than $100 \%$ in rivers of the Don basin and from $10 \%$ to more than $100 \%$ in rivers of the Volga basin. However, in the rivers of the northern ER, the increase in the runoff is less than 30\%. A schematic map in Fig. 4 shows this spatial variability. In the map, the circles of different size and colour demonstrate changes in the values of winter flow.

For water management, in addition to estimates of the average winter runoff, it is important to assess the main hydrological characteristics that limit the potential water diversion from the river. These characteristics include the minimum water discharge and the rate of winter runoff depletion. More than $80 \%$ of the hydrological gauges that have been studied for the period from 1975 have an ascending trend not only for the average winter flow, but also for the average monthly maximum and minimum flow. This, in turn, determines the change in the basic characteristics of winter low water, such as the rate of winter runoff depletion. As in the case of the changes in the rate of winter flow, the changes in the minimum and maximum monthly runoff in the winter lowflow period are largest in the central and southern ER.

There are spatial and temporal differences in the change in the average monthly water discharges. Changes in the average monthly water discharges were calculated separately for each month by analogy with the average values of the winter flow (Fig. 5). These changes are averaged over three regions: the Volga basin, the Don basin, and the river basins in the northern ER.

The rivers of the Don basin show a maximum change in the average water discharges in the period from August to November; while the rivers of the Volga basin, from January to March. For the rivers of the northern ER, such months are December and April. It should be noted that, against the background of the overall increase in the winter flow, there is a decrease in the monthly runoff in the early spring flood months. Conclusions can be made about the contribution of each season or month to the changes in the annual water runoff. Thus, the cause of these changes can be found. So, on the rivers of the Don basin, the changes are characterized by increased water discharges in the autumn. This may be caused by increased precipitation. The increased winter runoff in the rivers of the Don and Volga basins is caused by a shift in the dates of beginning of winter lowwater period and an increase in the number of thaws in this time. 


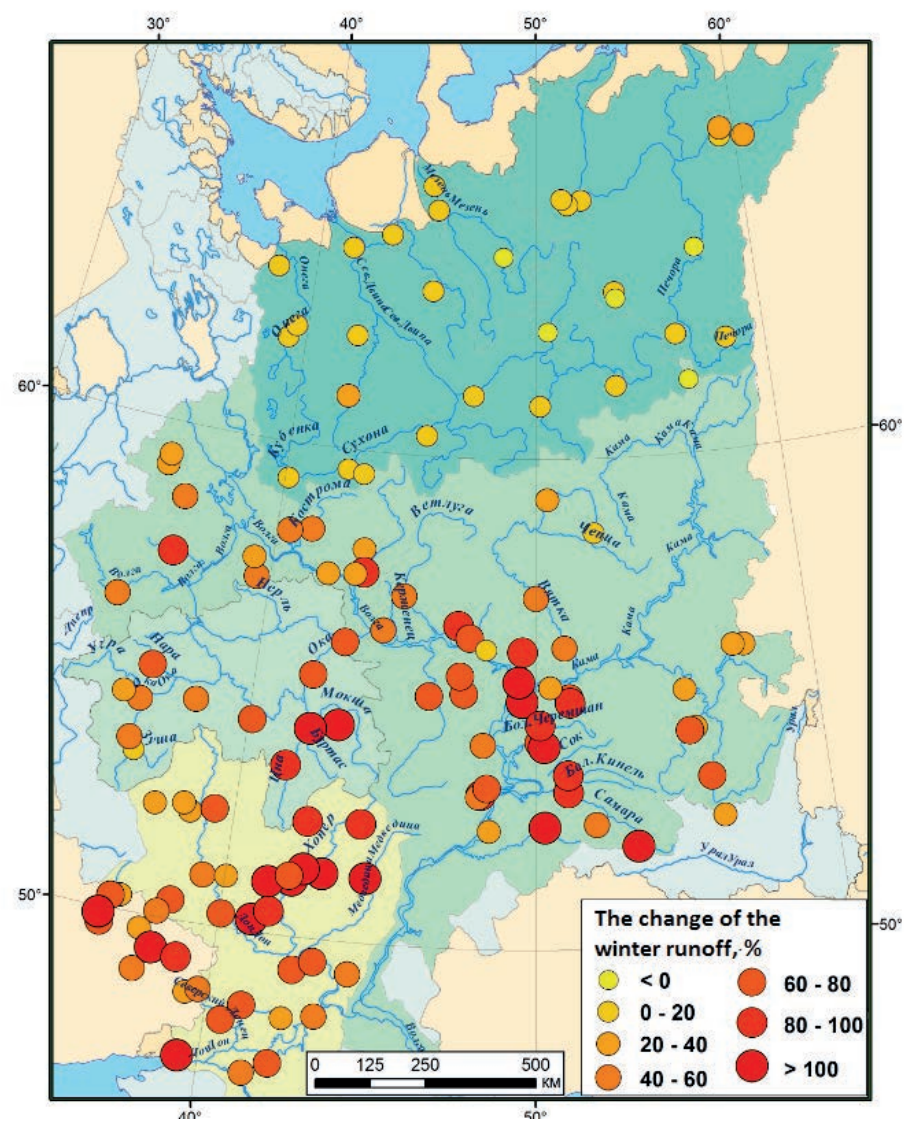

Fig. 4 Changes in the winter low-water flow in the rivers of Don and Volga basins and rivers in the northern European Russia for the period from 1975 to 2010 relative to the period from 1945 to 1974, in percent.

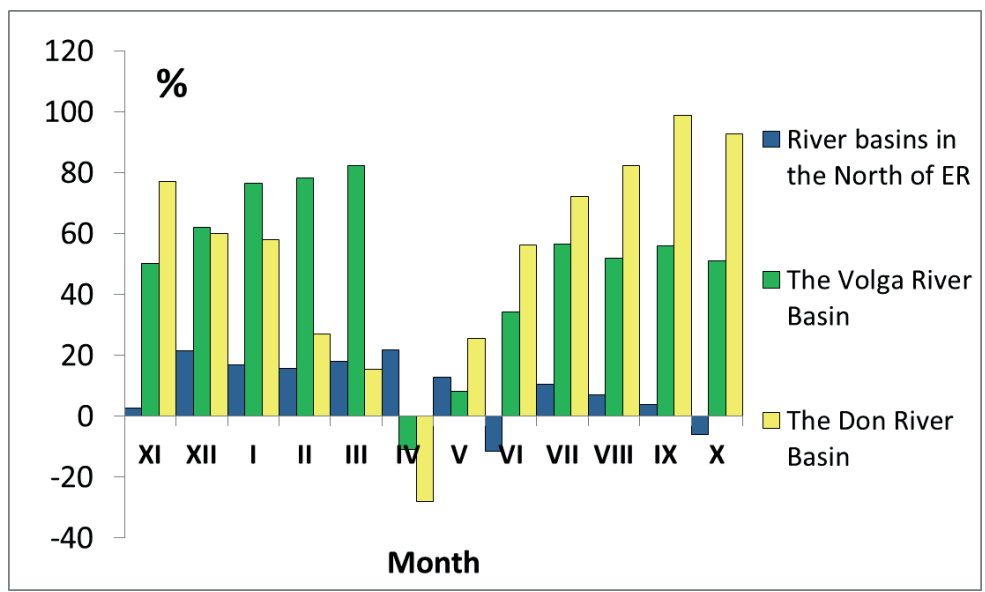

Fig. 5 Changes in the average monthly discharges, which have been averaged over three regions: the Volga Basin, the Don Basin and the river basins in the northern ER for the period from 1975 to 2010 relative to the period from 1945 to 1974 , in percent

\section{CONCLUSIONS}

Climate is changing in European Russia. This involves an increase in surface air temperature and precipitation. These climate changes affect, directly or indirectly, the flow of the rivers during the year. Milder winter temperatures and an increase in the number of thaws have led to increased winter runoff in Russia after 1975 due to additional inflow of snowmelt and rainwater 
(Georgievskii 2008, Shiklomanov et al. 2010). In this paper, we studied changes in winter lowwater runoff. The result of this work at this stage is that ER shows an increase in this characteristic. Calculations showed an increase in the size of winter runoff at more than $95 \%$ of hydrological gauges. For $82 \%$ of hydrological gauges on rivers in the basins of the Volga and Don and for $43 \%$ of the rivers in the northern ER, this ascending trend was significant. Some zoning can be identified in the increase in the winter water discharges from the south to the north in the ER. This is caused by landscape and climatic factors in combination with features of the geological and geomorphological structure of small watersheds and hydrogeological conditions.

Variations of winter runoff implicate changes in natural groundwater resources. At the regional scale, this was estimated by the low-water flow in rivers. Increasing the degree of flow control, typical of many of the rivers of the ER, will increase the reliability of water supply, especially during the winter runoff low. This should be taken into account in water management.

Acknowledgements The study was supported by the Russian Foundation for Basic Research, project no. 14-17-00700.

\section{REFERENCES}

Georgievskii, V.Yu. (2005) Changing of river runoff of Russia and water balance of the Caspian Sea under the influence of economic activity and global warming. Thesis abstract for the degree of Doctor of Geographical Sciences, St. Petersburg, SHI 39.

Kislov, A. and Babin, E. (2008) Mesoscale atmospheric circulation model as a means of interpolation of meteorological fields with high spatial resolution. Bulletin of Moscow University Series 5, Geography 4, 17-21.

RosHydromet (2012) Report on the peculiarities of climate on the territory of the Russian Federation in 2011. M. RosHydromet $83 \mathrm{p}$.

RosHydromet (2013) Report on the peculiarities of climate on the territory of the Russian Federation in 2012. M. RosHydromet $86 \mathrm{p}$.

Shiklomanov, I.A., et al. (2010) Problems of formation and evaluation of changes in water resources and water availability in Russia. Meteorology and Hydrology 1, 23-33. 